\title{
Public views on drought mitigation: Evidence from the comments sections of on-line news sources
}

\author{
Russell-Verma, S., Smith, H.M., and Jeffrey, P. \\ Cranfield Water Science Institute, Cranfield University, College Road, Cranfield, Beds, \\ MK43 0AL.
}

\begin{abstract}
During the Spring of 2012 much of the south-east of England was under water use restrictions, as a result of two consecutive dry winters. The drought highlighted the region's vulnerability to this natural hazard and emphasized the issues associated with water shortages and the need for drought mitigation measures. Using qualitative content analysis of online news articles $(n=14)$ and their associated comments from readers $(\mathrm{n}=1,298)$ we explore both public preferences for drought mitigation options and the underpinning reasoning used to justify such preferences. Findings suggest that supply side interventions attract more intense commentary and divide opinion to a greater extent than demand side strategies and that dialogue around mitigation options is characterised by a pronounced concern for the relative social justice of choices. The study also generates important lessons about the structured use of on-line public opinion sources and we offer conclusions about how these might best be utilised in the future.
\end{abstract}

Keywords: drought, mitigation, on-line, preferences, news. 


\section{Introduction}

On April $5^{\text {th }}$ 2012, following two consecutive dry winters (Kendon et al 2013) and four to six weeks of speculation, seven water companies in England (Anglian Water, Thames Water, Southern Water, South East Water, Sutton \& East Surrey, Veolia Central and Veolia South East) imposed a hosepipe ban on their customers. The water restrictions included prohibitions on watering gardens, washing cars, windows, paths or patios with a hosepipe, and filling paddling pools, swimming pools or ornamental fountains. Those found breaching the ban were liable to a maximum fine of $£ 1000$. The water companies progressively lifted the ban between June and July 2012. Both the drought (this was the term used in the media) and the resultant hosepipe ban were major news stories between late February and late July of 2012 with media outlets brimming with articles discussing the rights and wrongs of the hosepipe ban and displaying photographs of low reservoirs and dry river beds. Online media coverage included encouragement for readers to provide feedback and thoughts on the water restrictions via comment sections (typically located beneath the story itself). The purpose of the study reported here is to explore the general public's preferences for drought interventions and to identify the factors that influence those preferences using online news articles and the comments and opinions sections associated with those articles.

By definition floods and droughts occur infrequently. Yet they catalyse strong sentiments in affected populations and provide opportunity for wider criticism of technological sand management systems that, for $99 \%$ of the time, deliver reliable, safe, and equitable services. Unlike flooding, drought, from an experiential perspective, is a slow moving phenomenon with the imbalance between supply and demand becoming acute over weeks or even months until reactive measures such as hosepipe bans or pressure reductions are needed to conserve the resource. Public response to drought is therefore often triggered by drought mitigation interventions rather than to climatic change per se. In addition to criticism of those in control of water services, public commentary around drought events is also rich with proposals for how to rectify the existing situation and lower the risk of drought in the future. Such remarks, though opportunistic, offer a window into citizens' preferences for drought mitigation options. They can also indicate the rationale behind intervention preferences, exposing a 
dialogue of advocacy and criticism that illustrates lay understandings of the problem and provides subtle clues as to the acceptability of different options. Expressed preferences for drought mitigation options will also be shaped by the role which water plays in societal culture and much commentary on individual and community responses to hydrological extremes urges wider understanding of the 'cultural domain' which often shapes both the mood and language of public reaction. Provoked by early contributions from Elizabeth Shove (2003) on the sociology of consumption, the use of a sociotechnical perspective as a nexus of understanding about the relationships between people and water has driven keen interest in how other academic disciplines (e.g. history and anthropology) can help us characterise and interpret public responses to contemporary water management challenges (Sofoulis, 2005; Taylor et al, 2009). Informed by these insights, our study goes beyond enumerating and describing preferences to engage with the underpinning reasons for favouring intervention options. It is widely acknowledged that understanding peoples' perceptions of drought is likely to be an important factor for sustainable water management by pointing to barriers to behavioural change (Dessai \& Sims, 2010). We further argue that knowing which features of an intervention option are used to validate its use for drought mitigation will enrich our appreciation of how communities comprehend technological and other drought response mechanisms.

The on-line comment sections of newspapers and broadcasters provide a useful and almost real-time forum for public discussion and debate (Manosevitch and Walker, 2009) which can reflect public concerns and opinions that may otherwise not be articulated or made available (Bell, 2009). Indeed, the rise of online journalism and interactive media provides a widespread forum for discussing news articles, (Diakopoulos \& Naaman, 2011) and is changing the way that individuals and organisations share and seek information (Squiers et al, 2010). Online documents and in particular comment sections, are an up-to-date source of contemporary opinion. News outlets are also increasingly reporting reader or viewer reactions to new stories, making such comments part of the news item itself. As a new platform for public participation, web based news items constitute a significant and easily accessible forum for public discussion (80\% of UK households had internet access in 2012 according to the Office of National Statistics). Previous studies by Nip (2006) have indicated that this new form 
of interactive journalism can help both public and private sector institutions connect with communities, engage with individuals as citizens, and orchestrate public debate and deliberation. Manosevitch and Walker (2009) argue that one of the strengths of online and interactive journalism is that it may generate novel insights from individuals and groups who have previously been excluded from or found it difficult to have their voices heard in public debate. Others have pointed out that online discussions also offer a variety of perspectives which would otherwise not be available and which can often catalyse previously unexplored candidate solutions to long term problems (Gastil, 2008).

To date most interactive media research has focussed on the contents of on-line blogs and in contrast there have been few studies on the content of reader comments to online newspapers and broadcast sites (Manosevitch and Walker, 2009). However, because of their role as a conduit for public reaction and opinion, the comment sections of online media sources are becoming a more common source of data for research seeking to understand how social and economic challenges are communicated and conceptualised (Sonnett et al, 2006). The comment sections of most online news outlets allow readers to offer their opinion and perspective on articles. The format may or may not require the reader to register with the news site and often does not require the reader to use their real name, (Hermida and Thurman, 2007) which can encourage more readers to contribute their opinion. However, one shortcoming of this anonymity is that it can lead to inappropriate and unsuitable language, uninformed opinion, and inaccurate information.

Although there have been relatively few studies examining the comments sections of online media, the few that are available offer enticing accounts of the potential value of such an approach. Content analysis has been used to examine how the comment sections of newspapers provide a unique and constructive space for public debate, providing a significant amount of factual information and promoting democratic discourse (Manosevitch and Walker, 2009). This study concluded that readers' comments sections are worthy of future research both as a phenomenon in their own right and as a source of contemporary opinion. A wider study of on-line sources was used by Squiers et al (2011) to explore public responses to new mammography screening recommendations 
in the USA, concluding that sector professionals gained a better understanding of public sensitivities to the proposals which could be utilised to structure communication strategies. More recently Milioni et al, (2012) explored whether social media websites give the public greater power to influence news coverage agendas. They used content analysis to examine readers' comments to a number of online publications to determine the extent to which readers supported or challenged the editorial line and the variety of positions taken by readers in response to a specific article.

The use of media copy in general (i.e. not including reader responses to articles) to study public responses to water issues has something of a more well established history. Of particular note are Bell's (2009) comparative analysis of press reports of the onset of drought in Sydney in 2002 and London in 2006 which demonstrated very different understandings of the relationship between infrastructure provision, individual behaviour and the environment. More recently, Sinoga \& Gross (2013) established the dynamics and evolution of the social perception of droughts in the context of global change, as they are influenced by the communications media, and Hurlimann \& Dolnicar (2012) found that water-related news reports in Australia are characterised by lack of inclusion of views held by various stakeholders, a low level of support of statements with scientific evidence, a low level of impartiality in the sense of reporting on opposing views and a relatively high level of hedging, meaning that the author signals that there is some uncertainly about the reported information.

The study reported here is perhaps more direct in its ambition than those discussed above but is nonetheless able to offer important insights into the relationship between drought events and the immediate logics of response that drive public opinion. Specifically we seek to enrich our understanding of media and public responses to drought by identifying what forms of intervention are (i) highlighted in media articles and (ii) proposed by the public in their comments as measures to mitigate the impacts of drought conditions. We also interpret the online commentaries to expose the underpinning motivations behind the promotion of specific interventions by the public. 


\section{Methods}

The online media stories and comments utilised for this research were easily accessible, available in large volumes, and inexpensive to access and use. They also had the advantage of being less time consuming to collate compared with other data sources. Data collection was conducted over a period of five weeks using seven UK based online media sources: BBC News, Sky News, the Daily Telegraph, the Times, the Daily Mail, the Daily Express and the Guardian/Observer. This broad mix of media sources comprising tabloids, broadsheets and television channels were chosen to ensure both diversity of coverage and responses from a wide spectrum of the population (the readership / viewing demographics of these seven media sources has healthy representation from all three major political parties). The websites of these news sources are globally accessible and, whilst the news stories themselves were UK based, comments on them could be posted by individuals from outside the UK. Therefore, the sample of comments is both self-selecting (generated by those who bothered to write a comment on the story) and, whilst arguably UK biased, likely to include data from individuals based outside of the UK. Articles published between $1{ }^{\text {st }}$ February 2012 and 30th April 2012 were included. The time period during which the data was collected ensured that discussions about the developing drought as well as responses in the immediate aftermath of the hosepipe ban announcement were captured. As some will remember, even though the hosepipe ban was not lifted until July 2012, it began to rain heavily about a week following its announcement in April (Kendon et al, 2013). The drought as such was consequently abruptly replaced by news items about flooding!

A three phase approach to data collation (Figure 1) was adopted to provide opportunities to both refine and quality control the final data set. Phase one consisted of identifying relevant news stories and articles using key words such as 'drought', 'hosepipe ban' and 'water restrictions'. The news items were not read in detail at this stage and were selected on the basis of their headlines, generating a collection of 122 articles. Phase two involved reading and reviewing this preliminary set of articles (but not the comments) to confirm their eligibility for inclusion in the final data set. Only those articles that referred specifically to the drought and included reader comments were retained, reducing the number of qualifying articles to 80 with an associated set of 
10,409 reader comments. The articles and their associated comments were copied and pasted into separate word documents and cleaned to remove ancillary web content such as banners and advertisements. At this stage of data preparation it became clear that, despite their headline titles, some articles and their associated comments were not germane to the focus of this study, resulting in their removal from the data set. For instance, two articles were removed because the majority of their comments were abusive - their limited relevant commentary around proposed interventions was impossible to separate from outright hostility towards particular segments of society, or towards other commenters. Because drought interventions were not the focal point of the commentary, but were used more as an excuse to voice underlying acrimonious views, these comments were not deemed relevant for the analysis. Additionally, two articles were removed because they contained only peripheral commentary on responses to drought, and seven articles were culled because the majority of the article fell outside the scope of the research (e.g. commented on the impacts of drought on agriculture and wildlife or reminisced over earlier drought events). In Phase 3, the resulting set of 69 articles (with 2,588 associated comments) were purposively sub-sampled to ensure that all seven media sources were equally represented and that a significant number of comments were included from each source. This process generated a final set of 14 articles and 1,298 reader comments.

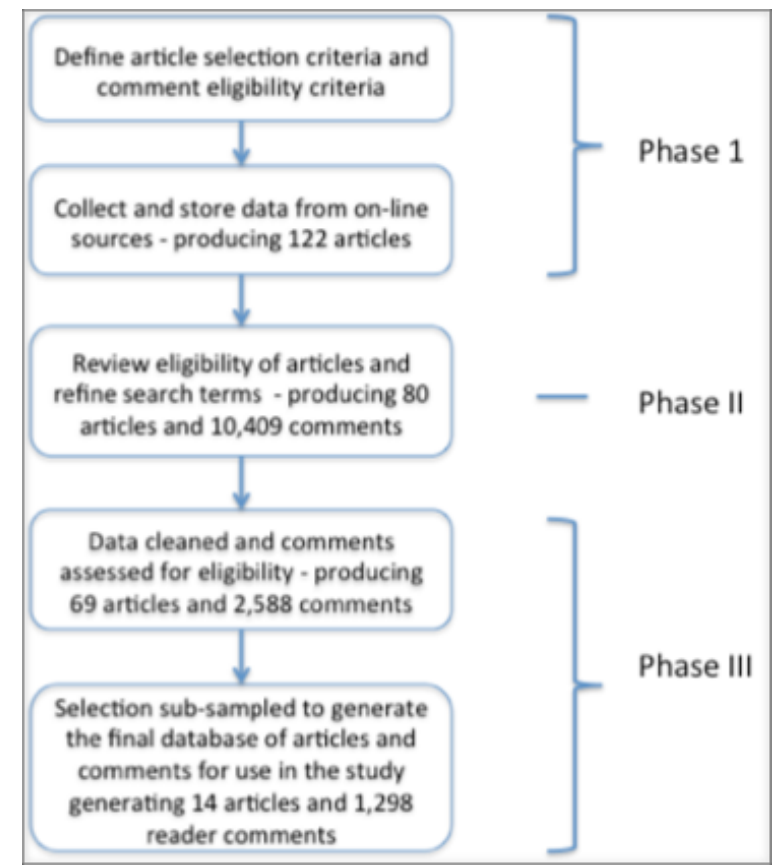

Figure 1 - Data collection \& collation flowchart
The fourteen articles selected for analysis (see Table 1 for details) retains the diversity of online media sources and editorial standpoints which informed the initial scan for sources (see above). Although most news sources, whether they be primarily televisual or print based, now have mature web presences, our sample draws from both mainstream TV news services (e.g. BBC, Sky) and 
newspaper publications (e.g. Express, Times). A diversity of political perspectives is also represented in the final sample with both right (e.g. Mail) and left (e.g. Guardian) leaning newspapers represented. The articles themselves were of varying lengths but all constituted substantive articles rather than merely news flashes. The shortest article contained 552 words, the longest 892 words, with the average article length being 687 words.

Table 1 - Articles selected for analysis

\begin{tabular}{|c|c|c|c|c|}
\hline $\begin{array}{l}\text { Article } \\
\text { ref } \\
\text { number }\end{array}$ & $\begin{array}{l}\text { Media } \\
\text { source }\end{array}$ & $\begin{array}{l}\text { Date of article } \\
\text { publication }\end{array}$ & Title of article & $\begin{array}{l}\text { Number of } \\
\text { relevant } \\
\text { comments }\end{array}$ \\
\hline 6 & Sky & $20 / 02 / 2012$ & $\begin{array}{l}\text { It's Official: South East In State Of } \\
\text { Drought }\end{array}$ & 66 \\
\hline 7 & Sky & $05 / 04 / 2012$ & $\begin{array}{l}\text { 'One In Three People Will Flout } \\
\text { Hosepipe Ban' }\end{array}$ & 90 \\
\hline 12 & Telegraph & $20 / 02 / 2012$ & $\begin{array}{l}\text { Drought declared in the south east of } \\
\text { England }\end{array}$ & 70 \\
\hline 24 & Telegraph & $03 / 04 / 2012$ & $\begin{array}{l}\text { Hosepipe ban: washing the patio could } \\
\text { cost you } £ 1000\end{array}$ & 36 \\
\hline 36 & Mail & $12 / 03 / 2012$ & $\begin{array}{l}\text { Diktats of the Drought Police. . . not } \\
\text { just a hosepipe ban, but } £ 1,000 \text { fines } \\
\text { for eleven offences on water use }\end{array}$ & 245 \\
\hline 41 & Mail & $02 / 04 / 2012$ & $\begin{array}{l}\text { So why can't Britain make sure we all } \\
\text { get enough water? Reservoirs are } \\
\text { overflowing in the North as South } \\
\text { suffers a drought }\end{array}$ & 81 \\
\hline 49 & Express & $13 / 03 / 2012$ & $£ 1,000$ fine for using hosepipe & 9 \\
\hline 50 & Express & $14 / 02 / 2012$ & $\begin{array}{l}\text { Britain faces drought crisis: water } \\
\text { shortage worst for } 90 \text { years }\end{array}$ & 11 \\
\hline 64 & Guardian & $05 / 04 / 2012$ & $\begin{array}{l}\text { How to reduce water consumption in } \\
\text { your home }\end{array}$ & 35 \\
\hline 66 & Guardian & $12 / 03 / 2012$ & $\begin{array}{l}\text { Spring hosepipe ban announced for } \\
\text { London and south-east }\end{array}$ & 37 \\
\hline 72 & Times & $21 / 02 / 2012$ & $\begin{array}{l}\text { Millions of families hit by worst } \\
\text { drought in } 30 \text { years }\end{array}$ & 12 \\
\hline 73 & Times & $27 / 04 / 2012$ & $\begin{array}{l}\text { Rainwater harvesting will reap huge } \\
\text { benefits }\end{array}$ & 12 \\
\hline 79 & $\mathrm{BBC}$ & $16 / 04 / 2012$ & $\begin{array}{l}\text { Hosepipe ban to be imposed in } \\
\text { drought-hit parts of UK }\end{array}$ & 298 \\
\hline 80 & $\mathrm{BBC}$ & $20 / 02 / 2012$ & $\begin{array}{l}\text { Drought summit as rivers in England } \\
\text { dry up }\end{array}$ & 296 \\
\hline \multicolumn{4}{|c|}{ Total Comments } & 1,298 \\
\hline
\end{tabular}


Content analysis of the articles and comments involved a mixture of deductive and inductive approaches, adapted from the account given in Elo and Kyngas (2007). The unit of analysis was a word, phrase or a sentence included in either the on-line article or an associated comment. Both the manifest content (stated) and latent content (implied, thus requiring interpretation) of the data set was explored. Early micro-analysis of three articles and their associated comments (as recommended by Strauss and Corbin, 1998) helped clarify the range of perspectives, idioms and grammars being used by contributors, thereby improving the quality of coding and interpretation during later stages of the analysis. Coding itself took place in two cycles, the first of which engaged with the intended unit of analysis (word, phrase or sentence) and the second of which generated themes and categories by grouping codes together. The repetitive activity of developing and modifying categories (by asking questions, comparing data and developing hierarchical categories) is a time consuming but crucial element of this type of analysis. Deductive hierarchical categories were used to identify intervention preferences and distinctions between supportive, opposing, and neutral responses were guided by a set of simile based descriptors (responses classified as 'supportive' indicated acceptance, adoption, approval, favour, positive reception, social acceptance, compliance etc.; responses classified as 'opposing' indicated resistance, rejection, postponement; neutral response indicated apathy, indifference, inertia). Inductive categories generated through close reading of the texts enabled emergent themes to be identified relating to the justifications used to support or oppose specific intervention options.

\section{Results \& discussion}

A total of fifteen different categories of drought mitigation intervention were mentioned in the articles (Figure 2) covering both supply and demand side options. 


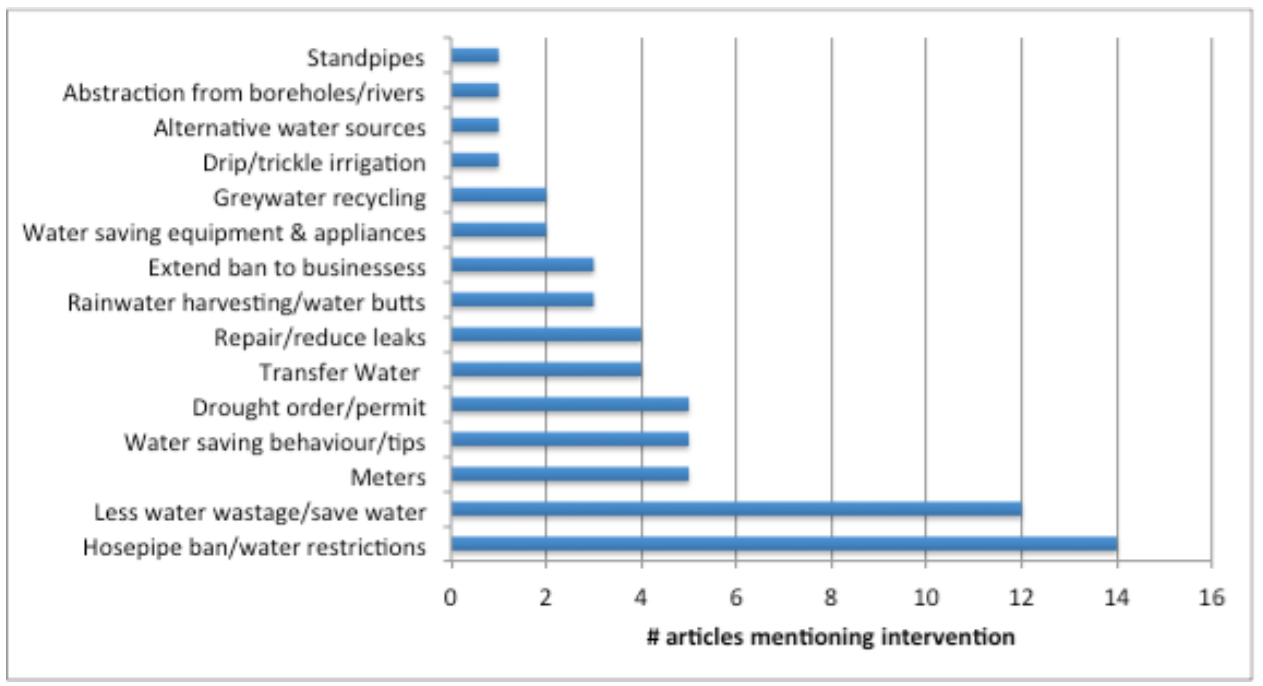

Figure 2 - Interventions reported in the online articles

Whilst the two types of intervention mentioned most frequently (hosepipe ban and generic incitement to use and waste less water) are clearly driven by the hosepipe ban story itself, there is a surprising variety of additional interventions mentioned in the articles. Article authors appear to be well informed about alternative approaches to tackling water shortages and, as a group, are able to articulate a spectrum of policy options ranging from the technological (e.g. drip irrigation) to the social (e.g. encourage water saving behaviour), and from the large scale (e.g. water transfers) to the small scale (e.g. metering). However, the distribution of intervention options does have an alarmingly long tail, suggesting that most articles only mention a small number of alternatives.

Widening the picture out to the comments sections of the reviewed articles generates an even more populous table of intervention options for consideration. Those commenting on the articles mentioned 20 different classes of intervention (Figure 3). Forms of intervention cited through the comments but not mentioned in the articles include investment in infrastructure and water pricing. Interestingly, two of the top three interventions supported in the comments sections (creating new reservoirs and desalination) are also not mentioned in any of the articles. 


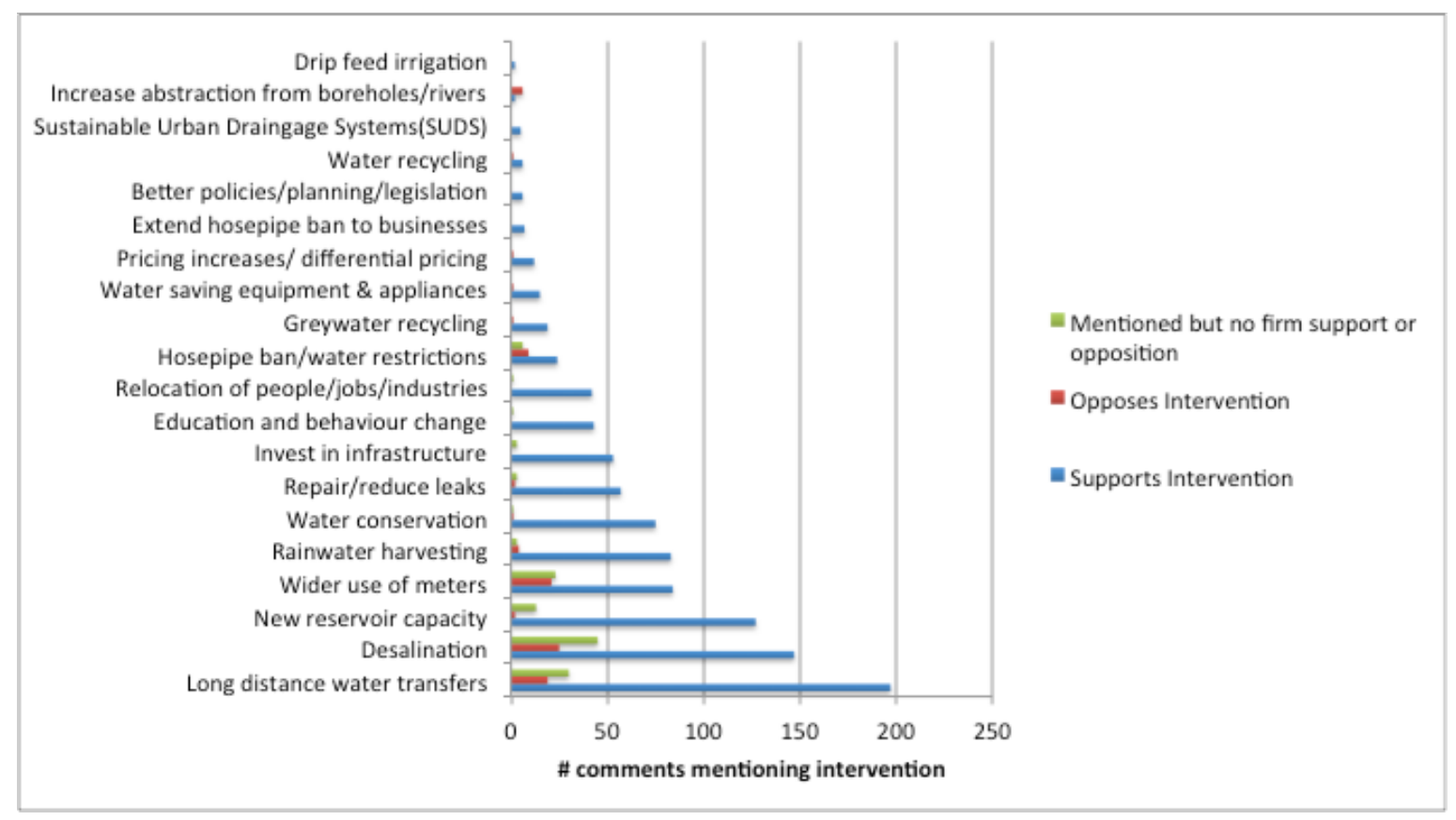

Figure 3 - Interventions mentioned in the readers' comments sections

The interventions mentioned through the comments sections fall into three broad groupings. The first of these contains intervention options that attracted high levels of positive comment, but were also relatively controversial. However, an assessment of the relative popularity of interventions needs to be tempered with an appreciation of the dialogic nature of the recorded interaction. So, although it appears as if (measured as a proportion of supportive comments) long distance water transfers, wider use of metering, desalination, and developing new reservoir capacity were the three most commonly supported options, these options also attracted relatively significant levels of comments objecting to the intervention. These options then are generating debate with individuals commenting on both positive and negative aspects. Intensity of positive reference is thereby not necessarily a sign that the intervention enjoys wide support and is not subject to varying opinions. A second set of interventions appear to be less contentious, attracting significant numbers of approving comments and little or no disapproval (water conservation, reducing leaks and wastage, investment in infrastructure, and education / behaviour change). These options can be characterised as consensual. The third group of options (e.g. water recycling and pricing) are mentioned relatively sparsely in the comments sections but again attract little opposition. 
One surprising feature of this dataset is that only one of the proposed interventions (abstraction from boreholes/rivers ) attracted more opposition than support. Even if the neutral comments are considered, there are more remarks of a positive tone than not. Several methodological influences could be at play here. Firstly, this was not a surveybased study and those commenting on the articles were not being asked a direct question. Consequently, opinion per se was not being elicited. The tenor or mood of comments and the relative proportion of supportive to negative comments is likely to have been shaped by the tone of the original article and of early comments in the timeline. All fourteen articles do indeed exhibit a constructive tone and this may have induced a progressive environment for debate. Secondly, and as noted above, comment streams (and their associated articles) that contained largely abusive comments were removed from the analysis. These included several particularly acrimonious exchanges (involving $6 \%$ of the articles originally identified) that might have rebalanced the ratio between positive and negative comments for several of the intervention types. Our desire to restrict the data to 'civilised' exchanges may well be hiding a community of opposition which perhaps too readily adopts confrontation and hostility as communicative tropes in order to get their point across but which still has important things to say about the relative desirability of different drought prevention measures.

The data presented in Figure 3 also indicates that supply side interventions (e.g. desalination, water transfers) attract more intense commentary and divide opinion more so than demand side strategies (e.g. water conservation). This could be viewed as unsurprising given that supply side interventions are more obviously capital intensive (and therefore a burden on either the public purse or water bills) and also potentially disruptive to communities. Although interesting from the viewpoint of professionals working in the water sector (who often classify interventions in these terms), this may be too simplistic an explanation as the dialogue captured through the comments sections universally failed to distinguish between supply and demand side options. Views for or against specific interventions were universally defended on the anticipated costs and merits of each individual option without reference to more strategic distinctions. However, there were many calls for 'balanced' or 'holistic' approaches to managing 
water resources more generally; a sentiment that will also find resonance with water professionals.

Unfortunately, any comparison between the findings reported in Figures 2 and 3 is impaired by the different metrics used. Specifically, the unit of analysis for Figure 2 is the article whereas that for Figure 3 is the comment. Additionally, the article based analysis focuses on mention of an intervention whereas the comments based analysis focuses on whether mention was made in a favourable or derogatory manner. However, the fact that two interventions of preference to those commenting on the articles were not referenced at all by the article authors (creating new reservoirs and desalination) and that a much wider set of options was mentioned by in the comments sections is worthy of note and some expansion. The fact that many more interventions are discussed in the comments sections than in the articles indicates that the pool of commenters was fairly well informed about the variety of possible drought mitigation options. However, it may also be the case that the relative 'popularity' of certain interventions could be a reflection of how well known they are. For example, people are more likely to have heard of and be familiar with the concept of desalination than water recycling. More broadly, we would argue that in the context of public understanding of, and engagement with, UK water policy these findings suggest that we are witnessing a mature public debate. A hosepipe ban is an emotive issue for many people and yet in the immediate aftermath of its announcement (and after removing abusive comments) we have observed a wide ranging, reasonably well balanced, and constructive debate on drought resilience measures from across a range of socio-political communities. Although debate at the margins of any sensitive issue is liable to descend into acrimony, the labels that might be used as descriptors for the dialogues exposed by our findings are 'well informed' and 'constructive'.

Readers' motivations for promoting or opposing particular interventions were also recorded. Figure 4 shows the number of times each of five motivations were referenced to justify support for, or opposition to, a particular intervention. Some explanation of the semantic connotation behind each of these motivations will aid interpretation. Arguments around 'trust' were concerned with confidence in both the ability of the 
technique being discussed to deliver impact and the trustworthiness of those responsible for its safe and effective implementation. Fairness was raised as a motivational factor where the impact of a particular intervention was thought to be unjustly or inconsistently distributed amongst the population. Used primarily as a reason to oppose an intervention, the lack of appropriate or timely Knowledge and Information was offered as a definitive argument for many options. Financial considerations reflected concerns about the cost-benefit balance of an option as well as its overall financial burden. Finally, some comments highlighted risks to public health which might emerge if some interventions were implemented too swiftly or without due consideration for standards.

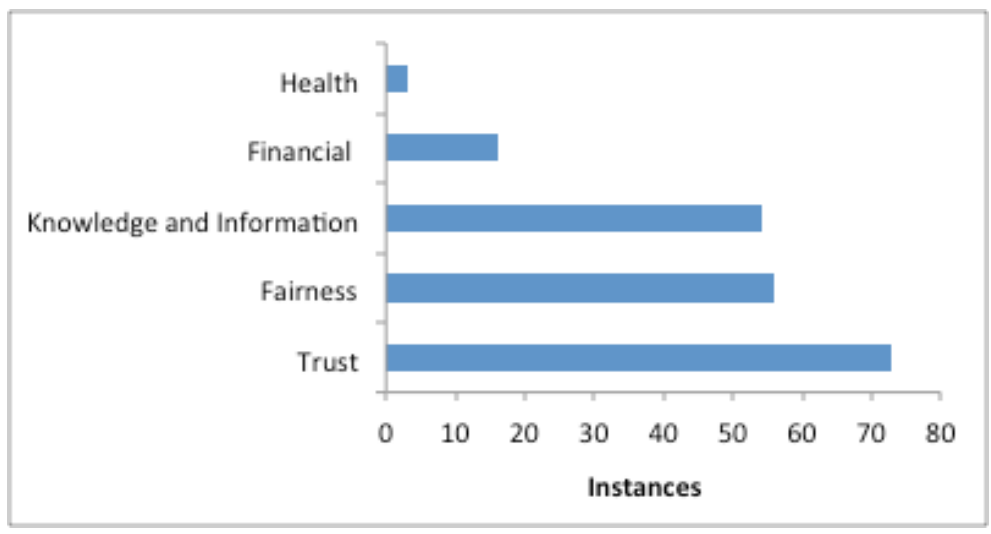

Figure 4 - Motivations for supporting or opposing interventions

That fact that two of the dominant motivations (trust and fairness) for preferring or opposing specific drought management interventions are associated with the social and political credibility of the option, rather than its cost or impact, is suggestive of wider developments in the relationship between utility management and society. It is well demonstrated that trust and fairness are important to individuals and communities which experience high levels of uncertainty around decision making (Jorgenson et al, 2006) and recent work in Australia has shown how such considerations become particularly dominant when water resources are under strain and tough decisions are needed on new innovative interventions and resource allocation (Nancarrow et al, 2010; Syme, 2013). Our results corroborate these insights, providing additional evidence from an 
independent context. They also highlight a particular challenge for regulators and water planners in that communities appear to be equally (if not more) concerned about the social justice of water management interventions as they are about their absolute costs and wider consequences.

More widely, our findings are comparable with those of Manosevitch \& Walker (2009) who argue that the comment sections of online news articles can offer a substantial amount of factual, narrative, source, values, position, and reasons information. Specifically, our work confirms this position with particular regard to the provision of data on 'position' and 'reasons'. Research by Ryfe (2006) shows that personal experiences are an important part of public discourse because they can help overcome barriers and help people understand the complexity of an issue through the process of personal reflection. This was widely evident in those comments categorised as neutral. The findings of this study confirm that interactive journalism can provide insights that the original newspaper article did not consider, and can offer an assortment of perspectives on a single issue. This is evident in the variety and quantity of interventions suggested by the readers.

\section{Conclusions}

We argue that two robust conclusions can be drawn from the data presented above. Firstly, the finding that supply side interventions attract more intense commentary and divide opinion to a greater extent than demand side strategies indicates a greater degree of comfort with this second class of drought mitigation options. Secondly, the fact that dialogue around mitigation options was characterised by a pronounced concern for the relative social justice of choices suggests that a wider agenda around decision integrity is being pursued by citizens. This has ramifications for the evolving relationships between water service providers and the societies in which they operate. For many water service providers, the standard measures for evaluating investments in particular options (e.g. operating and captial costs, environmental impacts, etc.) are often balanced against their impacts on customers via the affordability of water service bills. Our findings indicate that this concern for affordability may need to be broadened by an 
appreciation of communities' perceptions of the fairness and equitability of particular options.

However, although the relative level of support for different drought mitigation options exposed through this study is of interest, we argue that the more valuable elements of the study (for both researchers and practitioners) relate to lessons learned about the structured use of on-line public opinion sources. The method offers the potential for rapidly acquiring a snapshot of public attitudes in the wake of a drought or flood event and can likewise be used to gauge reactions and responses to proactive initiatives such as information campaigns. Used as a proxy longitudinal survey, online comments might provide an evidence base to enable the identification of prominent shifts in opinion and intended behaviour. Our methodology demonstrates the value of incorporating both deductive and inductive aspects of analysis as a means of capturing depth and richness in the data while maintaining a structured and rigorous approach. However, we would highlight one important point of caution with regard to the use of on-line comments. Context is all with respect to the interpretation of on-line material; particularly where that material is being generated in the light of a prominent national story, and in response to both a catalysing article, and comments from other readers. Our experience demonstrates that on-line comments provide a rich vein of information but that simply counting instances of support or opposition to water management options is a poor substitute for deeper reflection on the possible associations between different forms of evidence captured in the texts.

\section{Acknowledgements}

The research which informed this contribution was financed by the European Community's Seventh Framework Programme through the TRUST (Transitions to the Urban Water Services of Tomorrow) project - EC Contract \# 265122. 


\section{References}

Bell, S. 2009. The driest continent and the greediest water company: newspaper reporting of drought in Sydney and London. International Journal of Environmental Studies, 66(5), 581 -589 .

Diakopoulous, N., and Naaman, M., 2011. Towards quality discourse in online news comments. Proceeding of CSCW March 19-23, Hangzhou, China

Dishman, C.M, Sherrard, J.H. and Rebhun, M., 1989. Gaining support for direct potable water re-use. Journal of Professional Issues in Engineering, 115(2), 154-161.

Hurlimann, A., Dolnicar, S., 2012. Newspaper coverage of water issues in Australia. Water Research, 46(19), 6497-6507

Dessai, S. \& Sims, K., 2010. Public perception of drought and climate change in Southeast England. Environmental Hazards, 9, 340-357.

Domnech, L. and Saurí, D.A., 2010. Socio-technical transitions in water scarcity contexts: Public acceptance of greywater reuse technologies in the Metropolitan Area of Barcelona. Resources, Conservation and Recycling, 55(1), 53-62.

Elo, S. and Kyngas, H., 2007. The Qualitative Analysis Process. Journal of Advanced Nursing, 62(1), 107-15.

Gastil, J., 2008. Political communication and deliberation. Thousand Oaks, CA: Sage.

Hermida, A., and Thurman, N., 2007. Comments please: How the British news media is struggling with user-generated content. Proceedings of the 8th International Symposium on Online Journalism, University of Texas, Austin, USA, March 31st

Hurlimann, A., Dolnicar, S. and Meyer, P., 2009. Understanding behaviour to inform water supply management in developed nations - A review of literature, conceptual model and research agenda. Journal of Environmental Management, Vol. 91, No. 1, pp. 47-56.

Jorgensen, B.S., Syme, G.J., Nancarrow, B.E., 2006. The role of uncertainty in the relationship between fairness evaluations and willingness to pay. Ecological Economics, 56 (1), 104124

Kendon, M., Marsh, T. and Parry, S., 2013. The 2010-2012 drought in England and Wales. Weather, 68, 88-95.

Manosevitch, E. and Walker, D., 2009. Reader comments to online opinion journalism: A space of public deliberation. Proceeding of the $10^{\text {th }}$ International Symposium on Online Journalism, Austin, TX, April 17-18.

Milioni, D., Vadratsikas, K., and Papa, V., 2012. Their two cents worth': Exploring user agency in readers' comments in online news media. Observatorio Journal, 6(3), 1-26. 
Nancarrow, B.E., Porter, N.B., Leviston, Z., 2010. Predicting community acceptability of alternative urban water supply systems: A decision making model. Urban Water Journal 7(3), 197-210

Nip, J.Y.M., 2006. Exploring the Second Phase of Public Journalism. Journalism Studies, 7(2), 212-236.

Ryfe, D., 2006. The Nature of News Rules. Political Communication 23, 1-12.

Ruiz Sinoga, J.D., and León Gross, T., 2013. Droughts and their social perception in the mass media (southern Spain) International Journal of Climatology 33(3), 709-724

Shove, E. 2003. Comfort, Cleanliness and Convenience: The Social Organization of Normality, Oxford. Berg.

Sofoulis, Z., 2005. Big Water, Everyday Water: A Sociotechnical Perspective, Continuum: Journal of Media \& Cultural Studies, 19(4) 445-463

Sonnett, J., Morehouse, B.J., Finger, T.D., Garfin, G. and Rattray, N., 2006. Drought and declining reservoirs: comparing media discourse in Arizona and New Mexico, 2002-2004. Global Environmental Change, 16, 95-113.

Squiers, L.B., Holden, D.J, Dolina, S.E., Annice, E.K., Bann, C.M. and Renaud, J.M. 2011. The Public's response to the U.S. preventative services task force's 2009 recommendations on mammography screening. American Journal of Preventative Medicine, 40(5), 497-504.

Strauss, A.L. and Corbin, J., 1998. Basics of Qualitative Research: Techniques and procedures for developing grounded theory $\left(2^{\text {nd }} E d\right)$, Thousand Oaks, California. Sage.

Syme, G.J., 2014. Acceptable risk and social values: Struggling with uncertainty in Australian water allocation. Stochastic Environmental Research and Risk Assessment 28 (1) , pp. 113121

Taylor, V., Chappells, H., Medd, W., and Trentmann, F., 2009. Drought is normal: the sociotechnical evolution of drought and water demand in England and Wales, 1893-2006. Journal of Historical Geography, 35(3), 568-591. 